\title{
Hormone Ontogeny in the Ovine Fetus: XIX: The Effect of a Potent Luteinizing Hormone-Releasing Factor Agonist on Gonadotropin and Testosterone Release in the Fetus and Neonate ${ }^{1}$
}

\author{
SUSAN J. CLARK, ${ }^{2}$ BERTHOLD P. HAUFFA, ${ }^{3}$ KLAUS P. RODENS, ${ }^{4}$ DENNIS L. STYNE, \\ SELNA L. KAPLAN, AND MELVIN M. GRUMBACH \\ Department of Pediatrics, University of California San Francisco, San Francisco, California 94143
}

\begin{abstract}
To investigate further the role of the hypothalamic luteinizing hormone releasing factor (LRF) pulse generator and the pituitary LRF receptor in the regulation of gonadotropin secretion and gonadal steroidogenesis in the ovine $(O)$ fetus and neonatal lamb, we measured the increment (the difference between the concentration of plasma $\mathrm{LH}$ at time 0 and peak $\mathrm{LH}$ ) in oLH $\left(\Delta_{0} \mathrm{LH}\right)$ and $\mathrm{oFSH}\left(\Delta_{0} \mathrm{FSH}\right)$ responses to a potent LRF agonist, D-Trp ${ }^{6}$ Pro ${ }^{9}$ NEt-LRF (LRF-A), after consecutive daily doses in 17 ovine fetuses (six females, 11 males) and in 15 neonatal lambs (six females, nine males). Seven of the lambs had been studied as fetuses. In addition, plasma concentrations of testosterone $(T)$ and androstenedione $\left(\Delta_{4} A\right)$ were measured in nine male fetuses. After a stimulatory response to the first dose of LRF-A, the mean $\triangle o L H$ and $\triangle \mathrm{oFSH}$ responses in the 106- to 118-d gestation fetuses of both sexes were significantly suppressed by the fourth dose and in the neonatal lamb by the second dose. Suppression was sustained throughout the duration of LRF-A therapy which included the gestational interval when the fetal pituitary exhibits its greatest responsiveness to an acute dose of synthetic LRF. The duration of oLH and $\mathrm{oFSH}$ suppression after cessation of LRF-A therapy was studied by measuring the $\triangle \mathrm{oLH}$ and $\triangle \mathrm{oFSH}$ responses to LRF before and at intervals after LRF-A therapy. In the fetus, the $\Delta_{0} L H$ and $\Delta_{0 F S H}$ responses remained significantly decreased 7-8 d after the agonist was discontinued. No statistical differences were detected in the $\Delta 0 L H$ and $\triangle 0 F S H$ responses to LRF in the neonatal lamb at least by the 4th $d$ after discontinuation of LRF-A. Increasing the duration of LRF-A therapy did not prolong the length of recovery of LH and FSH responsiveness to LRF in either fetus or neonate. Mean fetal plasma $T$ levels rose significantly in response to a single dose of LRF or LRFA. Peak $T$ responses to single dose LRF or LRF-A were lower on $d$ 2-4 and $d 7$ than on the 1st $d$ of LRF-A
\end{abstract}

Received September 25, 1987; accepted November 16, 1988.

Correspondence and reprint requests to Melvin M. Grumbach, M.D., Department of Pediatrics. University of California San Francisco, San Francisco, CA 94143.

Supported in part by a grant from the National Institutes of Child Health and Human Development, NIH, USPHS.

'Presented in part in 1981 at the Sixty Third Annual Meeting of the Endocrine Society, Cincinnati, OH and the Society for Pediatric Research, Pediatr Res 15(:suppl)1543(abstr),1981.

Fellow in Pediatric Endocrinology under a program sponsored by NIDDK. Current address: Department of Pediatrics, Loma Linda University Medical Center. Loma Linda, CA 92350.

${ }^{3}$ Fellow in Pediatric Endocrinology sponsored by Deutsche Forschungsgemeinschaft.

${ }^{4}$ Fellow in Pediatric Endocrinology sponsored by the German National Scholarship Foundation.

\begin{abstract}
administration. These changes coincided with the decrease in the release of $\mathrm{oLH}$ and $\mathrm{oFSH}$. Peak $\mathrm{T}$ responses to a single dose of LRF or LRF-A had not returned to pretreatment levels by d 1-5 after discontinuation of chronic LRF$A$ administration in the male fetus. Plasma $\Delta_{4} \mathrm{~A}$ concentrations were not affected by chronic exposure to LRF-A. The results show that secretion of FSH and LH in the midgestation fetus is LRF-dependent. The induction of LRF desensitization in the fetal gonadotrope suggests that pulsatile gonadotropin secretion in the fetus is a consequence of pulsatile release of LRF. A relatively delayed recovery of LH and FSH responsiveness in the fetus may be due to a functional immaturity of the gonadotropes and their capacity to recover from desensitization, including down-regulation of LRF receptors. The increase in the concentration of testosterone after the administration of LRF is evidence of the bioactivity of fetal oLH. (Pediatr Res 25:347-352, 1989)
\end{abstract}

\section{Abbreviations}

oLH, ovine luteinizing hormone

oFSH, ovine follicle-stimulating hormone

$T$, testosterone

$\Delta_{4} \mathrm{~A}$, androstenedione

LRF, luteinizing hormone releasing factor

LRF-A, luteinizing hormone releasing factor agonist (D$\operatorname{Trp}^{6}$ Pro $^{9}$ NEt-LRF)

DHEA, dehydroepiandrosterone

IV, intravenous

Chronic administration of potent LRF-A, similar to continuous infusion of native LRF results, after initial stimulation of gonadotropin release, in desensitization of pituitary gonadotropes and suppression of gonadotropin secretion in experimental animals (1-11), adults (12) and children (13-15). However, nothing is known about the effect of chronic administration of LRF-A on pituitary-gonadal function in the fetus.

We previously reported that in the ovine fetus the plasma concentrations of oLH and oFSH rise to peak levels by midgestation and decline to low levels by term (16). The ovine hypothalamus contains immunoreactive LRF as early as $58 \mathrm{~d}$ of gestation (Styne DL, Gluckman PD, Kaplan SL, Grumbach MM, unpublished data). Further, the ovine fetal pituitary gland has the capacity to respond to exogenous LRF; the maximal increment in oLH occurs during midgestation when the mean 
gonadotropin concentrations are highest (17). These studies indicate that LRF receptors are present and functional in the fetal pituitary gland by midgestation, and that a readily releasable store of gonadotropins is present. Moreover, pulsatile LH secretion occurs in the fetus as early as $81 \mathrm{~d}$ of gestation (18). We postulated that at least by midgestation, $\mathrm{LH}$ and FSH secretion is not autonomous but rather it is dependent upon pulsatile LRF secretion by the fetal hypothalamic LRF pulse generator (18).

To characterize further the hypothalamic-pituitary gonadotropin apparatus in vivo in the fetus and neonatal lamb, we questioned whether chronic administration of a potent LRF-A would induce desensitization of fetal pituitary gonadotropes and suppression of gonadotropin secretion and if so, whether there was a difference in the response of the fetus and neonatal lamb; of special interest was the opportunity to determine whether fetal gonadotropin secretion in midgestation was LRF-dependent and also to assess the role of fetal hypothalamic LRF in the pulsatile release of LH and FSH in the fetus. Because of technical factors, it has not been possible to sample hypophyseal-portal venous blood or hypothalamic interstitial fluid in the fetus in vivo for LRF pulsatility.

In addition, we studied the changes in plasma $T$ and androstenedione $\left(\Delta_{4} \mathrm{~A}\right)$ in the male fetus to determine whether the desensitization of the fetal gonadotrope by chronic intermittent LRF-A administration is accompanied by a decrease in fetal testicular steroidogenesis.

\section{MATERIALS AND METHODS}

Animals and Experimental Procedures. Ewes of mixed Western breeding who were mated on a single occasion were used in these studies. Gestation in these animals is $147 \pm 3 \mathrm{~d}$. During our study, the ewes were maintained indoors with the same fixed lighting each day (from 0600 to 1900). After spinal anesthesia, catheters were placed in a maternal dorsalis pedis vein and artery. Hysterotomy was performed, as described previously (19), and the fetal neck exposed without removing the head from the uterus. Using local anesthesia, polyvinyl catheters were inserted into one carotid artery and one jugular vein. The uterus was then closed and catheters were externalized through a stab incision in the maternal flank. All studies were begun at least $48 \mathrm{~h}$ after surgery and were performed with the ewe standing quietly in a study cage. Fetal blood samples were obtained from the arterial catheter every $15 \mathrm{~min}$ for a maximum of $3 \mathrm{~h}$; LRF or LRF-A was infused into the venous catheter. Only fetuses with normal arterial blood gases ( $\mathrm{pH} \geq 7.33$ and $\mathrm{PO}_{2} \geq 18$ torr) were used in these studies.

The neonatal lambs were maintained indoors in cages with their mothers. All the lambs were fed by their mothers and were healthy and gaining wt normally. At $24-48$ h before the study, catheters were placed in the dorsalis pedis vein and artery using local anesthesia. All studies were performed with the lambs in a sling in close proximity to their mothers. LRF or LRF-A was administered IV, and blood samples were obtained from the arterial catheter every $15 \mathrm{~min}$ for $3 \mathrm{~h}$.

Experimental Groups. Both fetuses and neonates were studied as follows: The increment in $\mathrm{LH}(\Delta \mathrm{LH})$ and FSH $(\Delta \mathrm{FSH})$ is defined as the difference between LH and FSH at time 0 and the peak response. To evaluate the $\triangle \mathrm{oLH}$ and $\triangle \mathrm{oFSH}$ responses to LRF-A, a $10-\mu \mathrm{g}$ bolus was given daily for $2-7$ consecutive $\mathrm{d}$ in the fetus and for 2-14 consecutive $\mathrm{d}$ in the neonate. To assess the recovery of pituitary LH and FSH secretion after LRF-A treatment, the response to synthetic LRF after treatment with LRF-A was compared to the response to LRF before treatment with LRF-A. All animals were given LRF $5 \mu \mathrm{g}$ IV 1-6 d before LRF-A was administered (preagonist) and again at intervals of 1-4 d for a total of 10-11 d after the last dose of LRF-A (postagonist). Samples were obtained every $15 \mathrm{~min}$ for LH and every $30 \mathrm{~min}$ for FSH for $1 \mathrm{~h}$ before and $2 \mathrm{~h}$ after LRF-A or LRF were given.
Fetuses. Seventeen fetuses (six females and 11 males) were studied beginning at 106-118 d of gestation. The fetuses were divided into three groups, all of whom received LRF-A as a $10-$ $\mu \mathrm{g}$ daily IV bolus for $2 \mathrm{~d}$ (one female and three males), $4 \mathrm{~d}$ (three females and three males), and $7 \mathrm{~d}$ (two females and five males). The postagonist LRF tests ( $5 \mu \mathrm{g}$ IV) were stared at $115-129 \mathrm{~d}$ of gestational age and completed at 123-132 d of gestational age.

In addition to the gonadotropin response, the $\mathrm{T}$ and $\Delta_{4} \mathrm{~A}$ responses to LRF-A treatment were tested in nine of the male fetuses. Plasma from the samples taken $15 \mathrm{~min}$ before and immediately before LRF-A or LRF administration and from the samples obtained at 60 and $45 \mathrm{~min}$ before LRF-A or LRF were pooled and assayed for $\mathrm{T}$ and $\Delta_{4} \mathrm{~A}$. The results of these two pooled plasma samples were averaged to give one baseline value. Similarly, plasma from the samples obtained at 45 and $60 \mathrm{~min}$ after LRF-A or LRF administration were pooled and assayed for $\mathrm{T}$ and $\Delta_{4} \mathrm{~A}$ concentrations to estimate the peak value.

Neonates. Fifteen neonatal lambs (six females and nine males) were studied at 9-17 d of age. Seven of the lambs (three females and four males) had previously been studied as fetuses. The neonatal lambs were divided into five groups with three lambs in each group. There were two males and one female in each group of lambs except the group given LRF-A for $4 \mathrm{~d}$, in which there were two females and one male. The fifth group of three lambs (one female and two males) received LRF-A $4 \mu \mathrm{g} / \mathrm{kg}$ dose for 7 consecutive d; the other four groups were given $10 \mu \mathrm{g} / \mathrm{d}$ of LRF-A. The postagonist LRF tests ( $5 \mu \mathrm{g}$ IV) were started at 19$35 \mathrm{~d}$ of age and completed at 24-41 d of age.

Hormone assay. Gonadotropins. Plasma oLH and oFSH were determined by homologous RIA and double antibody separation, as previously described (16). The sensitivity of the oLH assay was $0.01 \mathrm{ng}$ and the half-maximal displacement value was 0.05 ng. The within-assay coefficient of variation was $4.7 \%$, and the interassay coefficient of variation was $15.3 \%$. Cross-reaction with oFSH was $1.8 \%$ and with ovine $\alpha$-glycoprotein hormone subunit was less than $1 \%$. Values are expressed in terms of a highly purified oLH standard $\left(\mathrm{G}_{3} 256 \mathrm{DA}\right)$, obtained from Dr. Harold Papkoff (University of California, San Francisco) which has an immunopotency 2.8 times that of NIH-LH-S1 8 and a biopotency 2.75 times that of NIH-LH-S1. The sensitivity of the oFSH assay was $0.03 \mathrm{ng}$, and the half-maximal displacement value was 0.45 ng. The within-assay coefficient of variation was $7 \%$, and the interassay coefficient of variation was $11.2 \%$. Cross-reaction with oLH and the ovine $\alpha$-glycoprotein hormone subunit was less than $1 \%$. oFSH values are expressed in terms of oFSH standard $\mathrm{G}_{4} 211$ BP (Papkoff) which has an immunopotency 17 times that of NIH-FSH-S12 and a biopotency 60 times that of NIHFSH-S1.

Steroids. Tritiated $\left[1,2^{3} \mathrm{H}(\mathrm{N})\right], \Delta_{4} \mathrm{~A}\left(41.0 \mathrm{Ci} \cdot \mathrm{mmol}^{-1}\right)$, and $\left[1 \beta, 2 \beta^{3} \mathrm{H}(\mathrm{N}) \mathrm{T}\left(50.4 \mathrm{Ci} \cdot \mathrm{mmol}^{-1}\right)\right.$ were purchased from New England Nuclear Corp., Boston, MA. The radioactive steroids were purified by Celite chromatography before use (20). Nonradioactive steroids were obtained from Mann Research Laboratories, Inc., New York, NY. Antisera to $\mathrm{T}$ and $\Delta_{4} \mathrm{~A}$ were purchased from Optimox, Inc., Palos Verdes Peninsula, CA. T antiserum had a cross-reactivity of $1 \%$ for $\Delta_{4} \mathrm{~A}$. Cross-reactivity of the $\Delta_{4} \mathrm{~A}$ antiserum for $\mathrm{T}$ was $0.1 \%$.

Evaluation of steroid assay specificity: A modification of the chromatography system was tested using tritium-labeled steroids. When applied to a Celite microcolumn with an ethylene glycol stationary phase, $97.5 \%$ of labeled $\Delta_{4} \mathrm{~A}$ eluted in the least polar fraction (mobile phase: $100 \%$ isooctane, $3.5 \mathrm{~mL}$ ). A total of $90.1 \%$ of labeled DHEA eluted in the fraction of medium polarity (7\% ethyl acetate in isooctane, $3.5 \mathrm{~mL}$ ), and $96.1 \%$ of labeled T was recovered in the most polar fraction (15\% ethyl acetate in isooctane, $5 \mathrm{~mL}$ ). The $\Delta_{4} \mathrm{~A}$ fraction and the fraction containing $T$ were used.

Specificity of the steroid assays for use with fetal ovine plasma was assessed by cochromatography as previously described (21, 22). $6000 \mathrm{dpm}\left[{ }^{3} \mathrm{H}\right] \Delta_{4} \mathrm{~A}$ and $\left[{ }^{3} \mathrm{H}\right] \mathrm{T}$ were added to $2 \mathrm{~mL}$ pooled 
fetal ovine plasma from samples obtained in the basal state and during LRF stimulation. The dried ether extract was applied to a Celite column and eluted using the above described mobile phases. Fractions of $0.5 \mathrm{~mL}$ were collected for each mobile phase, and one-half of each fraction was counted to assess the amount of labeled steroid present. The other half was dried under nitrogen, and the amount of immunoreactive steroid in the residue was measured by RIA. The cochromatographic elution pattern for labeled and immunoreactive $\Delta_{4} \mathrm{~A}$ and $\mathrm{T}$ were congruent. In agreement with previous observations (23), we found an immunoreactive peak in the last $0.5 \mathrm{~mL}$ of the $\mathrm{T}$ fraction that also cross-reacted with the $\Delta_{4} \mathrm{~A}$ antiserum. These unknown crossreactants were eliminated from the $\mathrm{T}$ fraction by excluding the last $0.5 \mathrm{ml}$ of all the eluants of the $\mathrm{T}$ fraction.

Steroid RIA: $2000 \mathrm{dpm}\left[{ }^{3} \mathrm{H}\right] \Delta_{4} \mathrm{~A}$ and $\left[{ }^{3} \mathrm{H}\right] \mathrm{T}$ were added to the fetal sheep samples to allow for correction of procedural losses. After ether extraction and chromatography, the dried residues of the $100 \%$ isooctane fraction were assayed for immunoreactive $\Delta_{4} \mathrm{~A}$, and the $15 \%$ ethyl acetate/isooctane fraction was assayed for $\mathrm{T}$ immunoreactivity, as previously described (20).

The sensitivity of the assay expressed as the minimum detectable amount of steroid/tube was $5.8 \mathrm{pg} \Delta_{4} \mathrm{~A}$ and $6.7 \mathrm{pg} \mathrm{T}$, respectively. Combined intraassay and interassay variability were calculated according to the method of Rodbard (24). Intraassay coefficient of variation in the $\Delta_{4} \mathrm{~A}$ assay was $9.1 \%$ (low concentration range $22.8-37.2 \mathrm{ng} / \mathrm{dL}$ ) and $10.8 \%$ (high concentration range $86.8-134.1 \mathrm{ng} / \mathrm{dL}$ ); the $\Delta_{4} \mathrm{~A}$ interassay coefficient of variation was $12.9 \%$ and $6.4 \%$, respectively. Intraassay variability in the $\mathrm{T}$ assay was $6.6 \%$ (medium concentration range $60.6-70.5$ $\mathrm{ng} / \mathrm{dL}$ ) and $8.0 \%$ (high concentration range $242.7-280.3 \mathrm{ng} / \mathrm{dL}$ ); interassay variability was $6.5 \%$ for both concentration ranges.

LRF agonist: The potent LRF agonist LRF-A was kindly provided by Dr. Jean Rivier and Dr. Wylie Vale (The Salk Institute, La Jolla, CA). The potent LRF-A was selected because it binds to high affinity LRF receptors and can be given once/d.

Statistical analysis. The Wilcoxon signed rank test was used to compare the incremental response in gonadotropin $(\Delta \mathrm{oLH}$ and $\Delta \mathrm{oFSH})$ and steroid $\left(\mathrm{T}, \Delta_{4} \mathrm{~A}\right)$ levels during LRF-A treatment and the preagonist and postagonist responses to LRF testing. A $p$ value of $\leq 0.05$ is significant.

The gonadotropin responses in the three groups of fetuses and five groups of neonates were first compared using the KruskalWallis test. The gonadotropin responses between groups were compared on d 1, 4, and 7 of LRF-A treatment in the fetuses and $\mathrm{d} 1,4,7$, and 14 in the neonatal lambs. In addition, the gonadotropin responses to the preagonist dose of LRF and those on $d 3-4,7-8$ and $10-11$ postagonist were compared between groups. As significant differences in the gonadotropin responses during LRF-A treatment or recovery were not detected between animals treated for different lengths of time or with different $/ \mathrm{kg}$ doses, treatment and recovery data for these groups were pooled.

The 1-way ANOVA was used to compare the fetal and neonatal gonadotropin responses to LRF-A. Regression analysis was used to determine if there was a correlation between the response to LRF and the response to LRF-A. The differences between males and females were analyzed by the $t$ test. The gonadotropin response to the initial dose of LRF and LRF-A in the animals studied before and after birth was analyzed by the paired $t$ test.

Steroid data were tested for deviation from the normal distribution by graphic methods using the normal probability scale (25). When normalization could be achieved by logarithmic transformation, the paired $t$ test was used on the log transformed data; otherwise, the Wilcoxon paired-sample test was applied.

\section{RESULTS}

After initial stimulation of gonadotropin secretion on $d 1$ of LRF-A administration, suppression of LH and FSH secretion occurred in both the fetuses and the neonatal lambs. In the fetus on $\mathrm{d} 2$ of LRF-A the $\Delta$ peak oLH was reduced, and by $\mathrm{d} 4$ the decreased suppression was highly significant $(p \leq 0.005)$ (Table 1 ); suppression was maintained during daily administration of LRF-A for $7 \mathrm{~d}$. Similarly, in the neonate the $\Delta$ peak oLH responses to LRF-A were highly significantly decreased by the second dose $(p \leq 0.005)$ and remained suppressed with continued treatment for $14 \mathrm{~d}$. For FSH, both the fetal and neonatal responses to LRF-A were significantly decreased by the 4th $d$ in the fetus $(p<0.005)$ and the 2 nd $d$ in the neonate. After $4 \mathrm{~d}$ of LRF-A administration in the fetus and $2 \mathrm{~d}$ of administration in the neonatal lamb, no further suppression of LH or FSH secretion occurred.

All male fetuses responded to each dose of LRF or LRF-A with a significant rise of plasma $\mathrm{T}$ above the basal level $(p<$

Table 1. The $\Delta o L H(n g / m L)$ and $\triangle o G S H(n g / m L)$ response to $L R F-A(10 \mu g I V)$ and to $L R F(5 \mu g I V)$ before and at intervals after $L R F-A^{*}$

\begin{tabular}{|c|c|c|c|c|c|c|c|c|c|}
\hline & \multirow[b]{2}{*}{ LRF: preagonist } & \multicolumn{4}{|c|}{$\begin{array}{l}\text { During administration } \\
\text { of LRF-A }\end{array}$} & \multicolumn{4}{|c|}{$\begin{array}{c}\text { LRF after } \\
\text { discontinuation of LRF-A }\end{array}$} \\
\hline & & 1 & 2 & 4 & 7 & $1-2$ & $3-4$ & $7-8$ & $10-11$ \\
\hline \multicolumn{10}{|l|}{ Fetus } \\
\hline$n$ & 16 & 17 & 3 & 13 & 6 & 3 & 9 & 10 & 9 \\
\hline oLH mean & $15.6^{1}$ & $20.5^{a}$ & 6.3 & $1.2^{b}$ & $0.9^{c}$ & 4.0 & $5.7^{2}$ & $7.8^{3}$ & 9.3 \\
\hline$\pm \mathrm{SEM}$ & \pm 1.9 & \pm 3.3 & \pm 3.8 & \pm 0.3 & \pm 0.1 & \pm 2.8 & \pm 1.7 & \pm 2.2 & \pm 2.5 \\
\hline$n$ & 16 & 17 & 4 & 13 & 6 & 3 & 11 & 10 & 9 \\
\hline oFSH mean & $2.0^{4}$ & $2.6^{f}$ & 0.4 & $0.7^{g}$ & $0.7^{h}$ & 0.7 & $1.3^{5}$ & $1.1^{6}$ & 1.1 \\
\hline$\pm \mathrm{SEM}$ & \pm 0.4 & \pm 0.4 & \pm 0.3 & \pm 0.1 & \pm 0.1 & \pm 0.3 & \pm 0.2 & \pm 0.2 & \pm 0.2 \\
\hline \multicolumn{10}{|l|}{$\begin{array}{l}\text { Neonatal } \\
\text { lamb }\end{array}$} \\
\hline$n$ & 15 & 15 & 9 & 12 & 9 & 3 & 14 & 15 & 14 \\
\hline oLH mean & 14.2 & $18.7^{a}$ & $6.7^{b}$ & $3.8^{\circ}$ & $4.5^{d}$ & $4.5^{3}$ & 8.8 & 16.5 & 19.1 \\
\hline \pm SEM & \pm 4.1 & \pm 6.4 & \pm 1.7 & \pm 1.5 & \pm 1.5 & \pm 1.0 & \pm 1.1 & \pm 3.4 & \pm 3.0 \\
\hline$n$ & 14 & 14 & 9 & 11 & 9 & 3 & 14 & 15 & 13 \\
\hline oFSH mean & 2.0 & 2.9 & $1.2^{g}$ & $1.5^{h}$ & $1.8^{i}$ & 0.5 & 1.9 & 1.7 & 1.9 \\
\hline \pm SEM & \pm 0.3 & \pm 0.5 & \pm 0.3 & \pm 0.2 & \pm 0.2 & \pm 0.2 & \pm 0.3 & \pm 0.3 & \pm 0.3 \\
\hline
\end{tabular}

* Significance levels in fetus: ${ }^{a} v s^{b}, p<0.005 ;{ }^{a} v s^{c}, p<0.02 ;{ }^{1} v s^{2}, p<0.005 ;{ }^{1} v s^{3}, p<0.025 ;{ }^{f} v s^{g}, p<0.005 ;{ }^{f} v s{ }^{h}, p<0.05 ;{ }^{f} v s^{i}, p=0.025$.

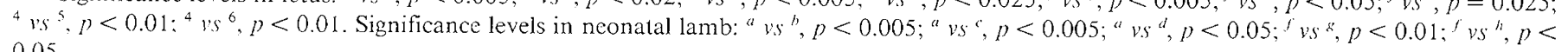
0.05 . 
0.05 ) (Table 2). Basal $\mathrm{T}$ concentrations before, during, or after LRF-A treatment did not differ significantly. The $T$ response to the first dose of LRF-A was not different from the $T$ response to native LRF. Peak $T$ responses on either the 2 nd or the 4 th $d$ of LRF-A administration were lower than the response to the first dose of LRF-A $(p<0.05)$. Lower peak responses were maintained on the 7th d of LRF-A treatment (versus d 1 of LRF-A $p$ $<0.05$ ). The basal and peak levels of $\Delta_{4} \mathrm{~A}$ were similar before $(21.9 \pm 5.0 \mathrm{ng} / \mathrm{dL})$ and during chronic LRF-A treatment $(25.7$ $\pm 4.1 \mathrm{ng} / \mathrm{dL}$ ).

In the fetuses and neonatal lambs, comparisons were made between the plasma LH and FSH responses to LRF before the administration of LRF-A and during recovery from desensitization by LRF-A after the discontinuation of the daily injections. As long as 7-8 d after discontinuation of LRF-A, the mean $\triangle \mathrm{oLH}$ and oFSH concentrations in the fetuses were significantly less than during the preagonist period ( $\mathrm{LH} p<0.005$, FSH $p<$ 0.01) (Table 1). By $10-11 \mathrm{~d}$, the mean fetal $\Delta \mathrm{oLH}$ and $\Delta \mathrm{oFSH}$ were similar to the responses before LRF-A administration. In contrast to the fetus, the $\triangle \mathrm{OLH}$ and $\triangle \mathrm{oFSH}$ responses to LRF in the neonates by $\mathrm{d} 3$ to 4 after discontinuation of LRF-A were not significantly different than the responses to LRF preagonist (Table 1).

No significant differences were detected in the $\Delta$ gonadotropin responses to LRF or LRF-A treatment or during recovery between the three groups of fetuses or the five groups of neonatal lambs (Kruskal-Wallis test: In the fetus: $\mathrm{LH}$, test statistic 0.042.2; FSH 0.2-4.1; critical value 5.99 when $\alpha=0.05$. In the lambs: LH, test statistic $1.5-6.46$; FSH, 6.02-6.43; critical value 9.49 when $\alpha=0.05$ ).

ANOVA was used to compare the fetal and neonatal gonadotropin responses to LRF-A. The fetal LH response was the same as in the neonate on $\mathrm{d} I$ and 2 of LRF-A treatment $(F(1,7)=$ 0.87 on $\mathrm{d} 1$ and $F(1,6)=0.84$ on $\mathrm{d} 2)$. The fetal $\mathrm{LH}$ response was significantly lower than the neonate on $\mathrm{d} 4$ and $7(F(1,21)$ $=14.5, p<0.01$ on $\mathrm{d} 4$ and $F(1,11)=16.2, p<0.01$ on $\mathrm{d} 7)$. The fetal FSH response was the same as in the neonate on $\mathrm{d} 1$ $(F(1,29)=1.006)$, but was lower than in the neonate on $\mathrm{d} 2,4$, and $7(F(1,10)=6.4, p<0.05$ on $\mathrm{d} 1,(F(1,23)=18.1, p<$ 0.001 on $\mathrm{d} 4$ and $F(1,13)=11.0, p<0.01$ on $\mathrm{d} 7)$.

There was a significant correlation between the rise in plasma LH and FSH in response to the preagonist dose of LRF and the first dose of LRF-A. (In the fetus: LH, $r=0.59, r^{2} 0.35, p=$ 0.016 ; FSH, $\left.r=0.76, r^{2}=0.58, p=0.0006\right)$. In the neonate:
$\mathrm{LH}, r=0.99, r^{2}=0.97, p=0.0001 ; \mathrm{FSH}, r=0.71, r^{2}=0.50, p$ $=0.0045$ ).

There was no significant difference between males and females in the gonadotropin responses to the preagonist $d$ of LRF and the first dose of LRF-A in either fetuses or lambs.

Finally, seven animals were studied both as fetuses and neonates. There were no differences between fetuses and neonates in the gonadotropin responses to the preagonist dose of LRF or the first dose of LRF-A.

\section{DISCUSSION}

Suppression of pituitary gonadotropes by consecutive daily doses of LRF-A was induced in the fetus and neonatal lamb. After a stimulatory response to the first dose, striking suppression of the oLH and oFSH responses to LRF-A occurred by the fourth daily dose in the fetus and by the second daily dose in the lamb. In the male fetus, a significant decrease in peak $T$ concentrations was observed concomitantly.

The decrease in gonadotropin release was sustained throughout the duration of LRF-A administration. The oLH responses to LRF remained suppressed after discontinuation of LRF-A for about 7-8 $\mathrm{d}$ in the fetus but not in the neonate. In the fetus, the postagonist LRF stimulation tests were performed before $132 \mathrm{~d}$ of gestational age as previous studies in our laboratory (17) showed that by $135 \mathrm{~d}$ of gestation a single dose of LRF elicited a smaller FSH and $\mathrm{LH}$ response than earlier in gestation.

The delayed recovery and continued suppression of $\mathrm{LH}$ and FSH release to the administration of LRF noted at 7-8 d postagonist in the fetus is most likely the result of persistence of desensitization of the gonadotrope by LRF-A. In contrast, the neonate demonstrated a more rapid recovery of pituitary sensitivity to LRF once LRF-A therapy was discontinued, suggesting a quicker escape from desensitization of gonadotrope function in the neonate; this difference may be attributable to a postnatal change in the functional maturity of the gonadotropes and their capacity to recover from desensitization including loss of LRF receptors. Increasing the duration of LRF-A administration did not lengthen the time of recovery of LH and FSH responsiveness to LRF in either the fetus or the neonate.

In the male fetuses, peak $T$ concentrations had not returned to pretreatment levels by $1-5 \mathrm{~d}$ postagonist. The response of plasma $T$ and $\Delta_{4} A$ to LRF and LRF-A in the male fetuses was studied between 106 and $125 \mathrm{~d}$ of gestation, when the peak

Table 2. Plasma $T(n g / d L)$ response to $L R F-A(10 \mu g I V)$ and $L R F(5 \mu g I V)$ before and at intervals after LRF-A in the male ovine fetus*

\begin{tabular}{|c|c|c|c|c|c|c|c|c|c|c|}
\hline \multirow[b]{3}{*}{ Male fetus } & \multicolumn{2}{|c|}{ LRF preagonist } & \multicolumn{6}{|c|}{$\begin{array}{l}\text { During administration } \\
\text { of LRF-A }\end{array}$} & \multirow{2}{*}{\multicolumn{2}{|c|}{$\begin{array}{c}\begin{array}{c}\text { LRF response } \\
\text { after }\end{array} \\
\begin{array}{c}\text { discontinuation of } \\
\text { LRF-A }\end{array} \\
\text { D } 1-5\end{array}$}} \\
\hline & \multirow[b]{2}{*}{ Basal } & \multirow[b]{2}{*}{ Peak } & \multicolumn{2}{|c|}{ D I } & \multicolumn{2}{|c|}{ D 2-4 } & \multicolumn{2}{|c|}{ D 7} & & \\
\hline & & & Basal & Peak & Basal & Peak & Basal & Peak & Basal & Peak \\
\hline 1 & & & 37.6 & 101.4 & 28.2 & 91.7 & & & 74.2 & 88.3 \\
\hline 2 & 50.9 & 79.0 & 72.6 & 95.6 & 32.2 & 49.3 & & & & \\
\hline 3 & 36.5 & 71.9 & 36.6 & 88.6 & 28.4 & 75.6 & 7.0 & 42.5 & 30.5 & 28.8 \\
\hline 4 & 41.7 & 66.1 & 25.4 & 54.7 & 19.5 & 49.2 & 16.8 & 50.6 & 26.2 & 33.8 \\
\hline 5 & 31.0 & 102.8 & 62.4 & 82.7 & 26.9 & 61.4 & 30.2 & 63.6 & & \\
\hline 6 & 31.3 & 96.5 & 31.2 & 111.9 & 34.8 & 51.7 & 24.2 & 78.9 & 18.5 & 39.9 \\
\hline 7 & 49.9 & 86.7 & 17.4 & 62.9 & 20.7 & 48.5 & 17.3 & 49.0 & 39.7 & 83.7 \\
\hline 8 & 28.0 & 53.0 & 12.0 & 61.0 & & 54.0 & & & 22.0 & 48.0 \\
\hline 9 & 8.0 & 31.0 & 22.0 & 62.0 & & & & & & 12.0 \\
\hline Mcan & 34.7 & $73.4^{1}$ & 35.2 & $80.1^{a}$ & 27.2 & $60.2^{b}$ & 19.1 & $56.9^{c}$ & 35.2 & $47.8^{2}$ \\
\hline \pm SEM & \pm 5.5 & \pm 8.3 & \pm 6.8 & \pm 6.9 & \pm 2.1 & \pm 5.5 & \pm 3.9 & \pm 6.5 & \pm 8.2 & \pm 10.7 \\
\hline
\end{tabular}

* Significance levels: ${ }^{a} v s^{b}, p<0.01 ;{ }^{a} v s{ }^{c}, p<0.05 ;{ }^{1} v s^{2}, p<0.05 ;{ }^{1} v s^{c}, p 0.005$. 
response of LH and FSH to LRF is maximal (17). The contribution of steroidogenic sites other than the fetal testes to circulating fetal plasma $T$ is uncertain. During this period of gestation, $T$ levels are higher in the male than in the female $(26,27)$. In an earlier study (27), a decrease in testicular $T$ content was noted towards late gestation, a stage when plasma $\mathrm{T}$ rises in the male ovine fetus. Our data show an increase in the concentration of plasma $T$ after acute administration of LRF and the first dose of LRF-A. The rise in T after native LRF and the first dose of LRFA coincides with the rise in plasma $\mathrm{LH}$ and FSH, suggesting a bioactive LH-dependent response and a gonadal source for the circulating $\mathrm{T}$. These observations support a functioning hypothalamic-pituitary-gonadal axis in the ovine fetus. By contrast, although the LH and FSH responses to LRF-A in the ovine fetuses almost disappear during LRF-A treatment, the basal T shows only a trend to lower concentrations. These results are most likely explained by residual basal bioactive $\mathrm{LH}$ secretion by the desensitized pituitary gonadotrope, by persistence of an $\mathrm{LH}$ effect on the fetal testes, or by a low amplitude pulse of $\mathrm{LH}$ evoked by the acute injection of LRF-A as a result of incomplete receptor blockade.

We documented the first decrease in the $T$ response to LRF during d 2-4 of LRF-A treatment, coinciding with the decrease in the $\mathrm{LH}$ response. This observation supports the concept of desensitization of the fetal gonadotrope to LRF, followed by decreased LH stimulation of the testes (28-31). The observation that the $T$ response to LRF administration did not return to preagonist levels by d 1-5 posttreatment is consistent with a reverse pattern of reactivation of the pituitary-gonadal axis after LRF-A treatment. A similar pattern is found in rams (8) and in children treated for true or central precocious puberty (14). We did not observe an inhibitory effect of chronic LRF-A administration on plasma $\Delta_{4} \mathrm{~A}$ concentrations.

The most potent LRF agonists have substitutions of a D-amino acid in position six and substitution of the glycine amide in the tenth position by ethylamide (10). D-Trp ${ }^{6}$ Pro $^{9}$ NEt-LRF is 140 times more potent than LRF and initially produces a striking elevation of plasma LH (32-35). The LRF analogs bind to high affinity receptors on the gonadotrope plasma membrane. Chronic administration of LRF agonist (in contrast to an acute dose) produces paradoxical desensitization of pituitary gonadotropes in animals and man (1-15) with suppression of gonadotropin secretion. This phenomenon has been associated with a decrease in receptor number $(4,33,34,35)$, but other poorly understood postreceptor mechanisms contribute to the decrease in gonadotropin secretion.

The present study provides evidence that specific LRF receptors are present in the sheep fetus by midgestation and that the fetal gonadotrope exhibits desensitization in response to the repeated daily administration of a potent LRF agonist. The desensitization of LRF receptors on the gonadotrope as evidenced by the suppression of the gonadotropin response by an LRF agonist is compelling circumstantial evidence for LRF secretion early in gestation. Previously, we demonstrated that the ovine fetus secreted LH and FSH in a pulsatile manner (18); the results of the present study would indicate that the fetal LRF pulse generator is operative at least by midgestation and the pulsatile release of hypothalamic LRF evokes the pulsatile LH secretion in the fetus.

In addition, this study supports a maturational change in the gonadotrope as demonstrated by the greater suppression of $\mathrm{LH}$ and FSH in the fetus than in the neonate during LRF-A treatment and by the more persistent suppression of LH and FSH secretion postagonist treatment in the fetus than in the neonate.

The decrease in T response to LRF-A is most likely secondary to the suppression of gonadotropin secretion by LRF-A. The timing of the changes in gonadotropin responses and in $\mathrm{T}$ in the male fetus makes a direct inhibitory effect of LRF-A on fetal steroid biosynthesis unlikely.
Acknowledgments. The authors thank Julien Hoffman, M.D., for his help with the statistical analysis, and Jennifer Radin for her assistance in the animal studies.

\section{REFERENCES}

1. Smith MA, Vale WW 1981 Desensitization to gonadotropin-releasing hormone observed in superfused pituitary cells on cytodex beads. Endocrinology 108:752-759

2. Vilchez-Martinez JA, Pedroza E, Arimura A, Schally A 1979 Paradoxical effects of D-Trp ${ }^{6}$-luteinizing hormone-releasing hormone on the hypothalamic-pituitary-gonadal axis in immature female rats. Fertil Steril 31:677682

3. Rivier C, Rivier J, Vale W 1979 Chronic effects of [D-Trp ${ }^{6}$ Pro $^{9} \mathrm{NEt}$ ] luteinizing hormone releasing factor on reproductive processes in the male rat. Endocrinology 105:1191-120

4. Pedroza E, Vilchez-Martinez JA, Coy DH, Arimura A, Schally AV 1980 Reduction of LH-RH pituitary and estradiol uterine binding sites by a superactive analog of luteinizing hormone-releasing hormone. Biochem Biophys Res Commun 95:1056-1062

5. Rivier C, Rivier J, Vale W 1978 Chronic effects of [D-Trp ${ }^{6}$ Pro $\left.{ }^{9}-N E t\right]$ luteinizing hormone releasing factor on reproductive processes in the female rat. Endocrinology 103:2299-2305

6. Sandow J, Von Rechenberg W, Jerzabek G, Stoll W 1978 Pituitary gonadotropin inhibition by a highly active analog of luteinizing hormone-releasing hormone. Fertil Steril 30:205-209

7. Fraser HM, Laird NC, Blakeley DM 1980 Decreased pituitary responsiveness and inhibition of the luteinizing hormone surge and ovulation in the stumptailed monkey (Macaca arctoides) by chronic treatment with an agonist of luteinizing hormone-releasing hormone. Endocrinology 106:452-457

8. Fraser HM, Lincoln GA 1980 Effects of chronic treatment with an LHRH agonist on the secretion of LH, FSH and testosterone in the ram. Biol Reprod $22: 269-276$

9. Sharpe RM, Fraser HM, Sandow J 1979 Effect of treatment with an agonist of luteinizing hormone on early maturational changes in pituitary and testicular function in the rat. J Endocrinol 80:249-257

10. Karten MJ, Rivier JE 1986 Gonadotropin-releasing hormone analog design: structure function studies toward the development of agonists and antagonists: rationale and perspective. Endocr Rev 7:44-66

11. Sundaram K, Thau RB, Goldstein M, Phillips DM, Rivier J, Vale W, Bardin CW 1984 Effect of an LHRH agonist on pituitary and testicular function in Rhesus monkeys. J Reprod Fertil 72:365-371

12. Vickery BH 1986 Comparison of the potential for therapcutic utilities with gonadotropin-releasing hormone agonists and antagonists. Endocr Rev $7: 115-124$

13. Crowley Jr WF, Comite F, Vale W, Rivier J. Loriaux DL, Cuttler GB 1981 Therapeutic use of pituitary desensitization with a long-acting LRF agonist: a potential new treatment for idiopathic precocious puberty. J Clin Endocrinol Metab 52:370-372

14. Styne DM, Harris DA, Egli CA, Conte FA, Kaplan SL, Rivier J, Vale W, Grumbach MM 1985 Treatment of true precocious puberty with a potent luteinizing hormone releasing factor agonist: Effect on growth, sexual maturation, pelvic sonography and the hypothalamic-pituitary gonadal axis. $J$ Clin Endocrinol Met 61:142-151

15. Luder AS, Holland FJ, Costigan DC, Jenner MR, Wielgosz G, Fazeekas ATA 1984 Intranasal and subcutaneous treatment of central precocious puberty in both sexes with a long-acting analog of lutcinizing hormone-releasing hormone. J Clin Endocrinol Metab 58:966-972

16. Sklar CA, Mueller PL, Gluckman PD, Kaplan SL, Rudolph AM, Grumbach MM 1981 Hormone ontogeny in the ovine fetus: VII: circulating luteinizing hormone and follicle stimulating hormone in mid and late gestation. Endocrinology 108:874-880

17. Mueller PL, Sklar CA. Gluckman PD, Kaplan SL, Grumbach MM 1981 Hormone ontogeny in the ovine fetus: IX: lutcinizing hormone and folliclestimulating hormone response to luteinizing hormone-releasing factor in mid- and late gestation and in the neonate. Endocrinology 108:881-886

18. Clark SJ, Ellis N, Styne DM, Gluckman PD, Kaplan SL, Grumbach MM 1984 Hormone ontogeny in the ovine fetus: XVII. demonstration of pulsatile LH secretion by the fetal pituitary gland. Endocrinology 115:1774-1779

19. Gluckman PD, Mueller PL, Kaplan SL, Rudolph AM, Grumbach MM 1979 Hormone ontogeny in the ovine fetus: I. circulating growth hormone in mid and late gestation. Endocrinology 104:162-168

20. Abraham GE, Manlimos FS, Garza R 1977 Radioimmunoassay of steroids. In: Abraham GE (ed) Handbook of Radioimmunoassay. Marcel Dekker, Inc., New York, pp 591-656

21. Buster JR 1980 Steroid radioimmunoassay applied to the study of animal models. In: Nathanielsz PW (ed) Animal Models in Fetal Medicine. Elsevier/ North Holland, Amsterdam, pp 313-368

22. Magyar DM, Elsner CW, Eliot J, Glatz T, Nathanielsz PW, Buster JE 1981 A combined radioimmunoassay for the measurement of unconjugated and sulfoconjugated $\Delta^{5}$ pregnenolone, 17-hydroxy- $\Delta^{5}$ pregnenolone, dehydroepiandrosterone and estrone applied to fetal and maternal ovine plasma. Steroids $37: 423-443$

23. Yu HK, Cabalum T, Jansen CAM, Buster JE, Nathanielsz PW 1983 Androstenedione, testosterone, and estradiol concentrations in fetal and maternal 
plasma in late pregnancy in the sheep. Endocrinology 113:2216-2221

24. Rodbard D 1974 Statistical quality control and routine data processing for radioimmunoassays and immunoradiometric assays. Clin Chem 20:12551274

25. Zar JH 1974 Biostatistical Analysis. Prentice-Hall, Englewood Cliffs, NJ, pp 124-126

26. Sklar CA, Mueller PL, Gluckman PD, Kaplan SL, Rudolph AM, Grumbach MM 1978 The ontogeny of gonadotropins and sex steroids in the sheep fetus. Pediatr Res 12(suppl):420(abstr)

27. Pomerantz DK, Nalbandov AV 1975 Androgen levels in the sheep fetus during gestation. Proc Soc Exp Biol Med 149:413-416

28. Sundaram K, Connell KG, Bardin DW, Samojlik E, Schally AV 1982 Inhibition of pituitary-testicular function with $\left(\mathrm{D}-\operatorname{Trp}^{6}\right)$ luteinizing hormonereleasing hormone in Rhesus monkeys. Endocrinology 110:1308-1314

29. Resko JA, Belanger A, Labrie F 1982 Effects of chronic treatment with a potent luteinizing hormone releasing hormone agonist on serum luteinizing hormone and steroid levels in the male Rhesus monkey. Biol Reprod 26:378384

30. Mann DR. Gould KG, Collins DC 1984 Influence of continuous gonadotropinreleasing hormone $(\mathrm{GnRH})$ and the testicular response to human chorionic gonadotropin in male Rhesus monkeys. J Clin Endocrinol Metab 58:262-
267

31. Dufau ML, Warren DW, Knox GF, Loumaye E, Castellon ML, Luna S, Catt KJ 1984 Receptors and inhibitory actions of gonadotropin-releasing hormone in the fetal Leydig cell. J Biol Chem 259:2896-2899

32. Vale W, Rivier C, Brown M, Rivier J 1977 Pharmacology of thyrotropin releasing factor (TRF), luteinizing hormone releasing factor (LRF), and somatostatin. In: Porter JC (ed) Hypothalamic Peptide Hormones and Pituitary Regulation. Plenum Press, New York, p 123

33. Clayton RN, Shakespear RA, Duncan JA, Marshall JC 1979 Radioiodinated nondegradable gonadotropin-releasing hormone analogs: new probes for the investigation of pituitary gonadotropin-releasing hormone receptors. Endocrinology 105:1369-1381

34. Jennes L, Stumpf WE, Conn PM 1984 Receptor-mediated binding and uptake of GnRH agonist and antagonist by pituitary cells. Peptides 5(suppl 1):215220

35. Loumaye E, Naor Z, Catt KJ 1982 Binding affinity and biological activity of gonadotropin releasing agonists in isolated pituitary cells. Endocrinology 111:730-736

36. Clayton RN, Catt KJ 1981 Gonadotropin-releasing hormone receptors: characterization, physiological regulation, and relationship to reproductive function. Endocr Rev 2:186-209 